Res Pública Revista de Historia de las Ideas Políticas

ISSN: $1131-558 \mathrm{X}$

http://dx.doi.org/10.5209/rpub.71281

\title{
¿Es posible el pensamiento de Žižek hoy?
}

\author{
Ricardo Espinoza Lolas ${ }^{1}$
}

Recibido: 1 de septiembre de 2020 / Aceptado: 14 de septiembre de 2020

Resumen. Este artículo busca reflexionar sobre el pensamiento de Žižek en la actualidad, en la era de Coronavirus, y ver cómo tal pensamiento tiene mucho que decirnos ante esta crisis mundial. Por una parte, ya no podemos seguir esperando en que acontezca una revolución, porque será otra mutación del Capitalismo que en vez de destruirlo lo hará más fuerte, pero, por otra parte, sí se puede esperar en esta crisis del Coronavirus que sea posible que acontezca otra forma de articularnos los unos a los otros, es el "amor" para Žižek; una cierta religión atea cristiana; a saber, una forma de entender el Comunismo hoy después de esta crisis mundial.

Palabras clave: Hegel; Amor; Capitalismo; Coronavirus; Žižek.

\section{[en] Is Žižek’s Thinking Possible Today?}

Abstract. This article seeks to reflect on Žižek's thinking today, at the time Coronavirus, and see how such thinking has a lot to tell us in the face of this global crisis. On the one hand, we can no longer wait for a revolution to happen, because it will be another mutation of Capitalism that instead of destroying it will make it stronger, but, on the other hand, in this Coronavirus crisis, it is possible that it is possible that Another way of articulating one another happens, it is "love" for Žižek; a certain Christian atheist religion; namely, a way of understanding Communism today.

Keywords: Hegel; Love; Capitalism; Covid-19; Žižek.

Sumario. 1. Introducción: Filosofía, Pandemia y Capitalismo. 2 Nosotros los "hegelianos" según el filósofo esloveno. 3 "Amor" en tiempos de Covid-19. 4. Por favor, ipor ahora no más revoluciones!. 5. Conclusión: devenimos muertos vivientes. 6. Bibliografía.

Cómo citar: Espinoza Lolas, R. (2020). ¿Es posible el pensamiento de Žižek hoy?. Res Pública. Revista de Historia de las Ideas Políticas, 23(3), 333-342.

"Durch die Wiederholung wird das, was im Anfang nur als zufällig und möglich erschien, zu einem Wirklichen und Bestätigten...”

"Lo único que está claro es que el virus destruirá los mismísimos cimientos de nuestras vidas, provocando no solo una enorme cantidad de sufrimiento, sino también un desastre económico posiblemente peor que la Gran Recesión. No habrá ningún regreso a la normalidad, la nueva «normalidad» tendrá que construirse sobre las ruinas de nuestras antiguas vidas, o nos encontraremos en una nueva barbarie cuyos signos ya se pueden distinguir. No será suficiente considerer la epidemia un accidente desafortunado, librarnos de sus consecuencias y regresar al modo en que hacíamos las cosas antes, realizando quizá algunos ajustes a nuestro Sistema de salud pública. Ten- dremos que plantear la siguiente pregunta: ¿qué ha fallado en nuestro Sistema para que la catásfrofe nos haya cogido completamente desprevenidos a pesar de las advertencies de los científicos? [The only thing that is clear is that the virus will shatter the very foundations of our lives, causing not only an immense amount of suffering but also economic havoc conceivably worse than the Great Recession. There is no return to normal, the new «normal» will have to be constructed on the ruins of our old lives, or we will find ourselves in a new barbarism whose signs are already clearly discernible. It will not be enough to treat the epidemic as an unfortunate accident, to get rid of its consequences and return to the smooth functioning of the old way of doing things, with perhaps some adjustments to our healthcare arrangements. We will have to raise the key question: What is wrong with our system that we were

\footnotetext{
Pontificia Universidad Católica de Valparaíso ricardo.espinoza@pucv.cl
} 
caught unprepared by the catastrophe despite scientists warning us about it for years?]"2.

Žižek, S., Pandemic! Covid-19 Shakes of the World...

"No es de extrañar que, tal como están las cosas ahora, China, en su amplio control social digitalizado, haya resultdo ser el país major equipado para enfrentarse a una epidemia catastrófica. ¿Significa ello que, al menos en algunos aspectos, China es el futuro? [No wonder that, as matters stand now, China, with its widespread digitalized social control, proved to be best equipped for coping with a catastrophic epidemic. Does this mean that, at least in some aspects, China is our future?]"3.

\section{Žižek, S., Pandemic! Covid-19 Shakes of the World...}

"De nuevo, la elección a la que nos enfrentamos es la siguiente: barbarie o algún tipo de comunismo reinventado [So, again, the choice we face is: barbarism or some kind of reinvented Communism]"4.

\section{Žižek, S., Pandemic! Covid-19 Shakes of the World...}

\section{Introducción: Filosofía, Pandemia y Capitalismo}

El pensamiento de Žižek se nutre de múltiples y variadas influencias, pero por lo menos hay dos referentes fundamentales y claros que siempre están presente en sus escritos ya de modo explícito como implícito: Teoría Crítica (Hegel, Marx, Adorno, etc.) y Psicoanálisis (Freud, Lacan, Miller, etc.). Sin embargo, lamentablemente tanto la Teoría Crítica como la Clínica Psicoanalítica en estos momentos hunden sus raíces en el propio Capitalismo; pienso en todo lo que trabaja Axel Honneth con su Teoría del Reconocimiento para la Socialdemocracia europea y americana; y no puedo dejar de nombrar a Jacques Alain Miller con todo su discurso muy radical para salvar al lacanismo de las "garras" del Populismo y del pensamiento de la izquierda radical (no olvidemos, el debate "contra" Jorge Alemán).

Y esto es más claro en estos tiempos en que el Capitalismo está mutando nuevamente en una nihilista y totalitaria forma; lo que llamo en mis libros como " $\mathrm{Ca}$ pitalismo hacendal militarizado chapuza": "Solamente hoy en el Capitalismo de la hacienda del territorio cerrado que nos sirve para cubrirnos y defendernos (contra un cierto enemigo, cualquier enemigo...) con todos nuestros valores identitarios chapuceros vulgares farsantes podemos generar nuestro emprendimiento seguro y gozar con ello" ". Este Capitalismo ya no es ni tardío ni neoliberal, es realmente una mutación más tóxica y "viral" y que se expande rápidamente por todas partes, su "contagio" llega a los rincones más insospechados; al abismo mismo de nuestro inconsciente; se puede ver esta mutación como una repetición mortífera porque todo intento

S. Žižek, Pandemia. La covid-19 estremece al mundo, Barcelona, Anagrama, 2020, p. 12.

Ibidem, p. 77.

Ibidem, p. 76.

R. Espinoza, NosOtros. Manual para disolver el Capitalismo, Madrid, Morata, 2019, p. 109. de vencer al Capitalismo lo vuelve a repetir más radical y se vuelve más indestructible (sobre esto volveremos más adelante); es como una nueva versión de la máquina de Terminator o de Doomsday (el enemigo que da muerte al mismo "inmortal" Superman de DC). Y este Capitalismo, a la vez, se transforma literalmente hoy en día por la Pandemia de Covid-19 bajo el mandato de China; pues ha sido la gran potencia capitalista que ha sabido salir airosa del influjo "maligno" del virus (la mortalidad de los infectados en 6 meses disminuyó casi a cero); y salió de forma militarizada y tecnológica.

La actualidad de la reflexión de Žižek se ve hoy con claridad total. Mientras termino este escrito, en el planeta acontece la Pandemia; su llegada a millones de humanos en múltiples países, entre otras cosas, ha producido un antes y un después de ciertas teorías filosóficas. Muchas de ellas se ven rancias, añejas y de otra época prepandémica, como la Teoría Populista de base en Laclau o el lacanismo teórico o la biopolítica como la de Agamben (ha sido patético lo ocurrido con este notable pensador italiano por su craso error inicial y su breve texto $L a$ invención de una epidemia, pero eso no invalida todo su excelente trabajo de años) ${ }^{6}$. Y en estos momentos vemos cómo Žižek tiene mucho que decir y de hecho lo dice de forma explícita por medio de sus textos, entrevistas, etc. El viejo y enfermo filósofo esloveno, tiene una diabetes muy avanzada, se hace notar en la crisis mundial y lo hace para expresar las lógicas que constituyen la Pandemia en tiempos de Capitalismo militarizado. Y ya publicó un libro a finales de marzo del 2020 (de forma precisa el 25 de marzo) dedicado a la influencia del virus SARS-Co-V-2 en el planeta y cómo esto nos trae una transformación del Capitalismo. Su libro se llama Pandemic! Covid-19 Shakes the World?.

Pero vayamos por partes. El Virus Corona (mal llamado en castellano como "Coronavirus") o como se le dice hoy internacionalmente a la enfermedad (sigla en inglés): Covid-19 (el virus se llama técnicamente SARS-CoV-2)... es otro virus (otro tipo de coronavirus, pues hay muchos), un cierto "en sí" (un "an sich" diría un hegeliano como Žižek), que aparece en este planeta (en China, ciudad de Wuhan, provincia de Hubei, a fines del 2019), ya sea por el motivo que sea (se dice de todo: desde castigo divino contra la nueva Sodoma planetaria a virus creado en USA para dañar la economía de los chinos pasando por un humano que comió algo "vivo" que no debía comer, etc.), y que como todos los virus trae una cierta "actualización" que "para nosotros" (un "für uns" también hegeliano y fundamental para entender a Žižek) los humanos ${ }^{8}$ (porque al parecer a nuestras mas-

G. Agamben, https://ficciondelarazon.org/2020/02/27/giorgio-agamben-la-invencion-de-una-epidemia/

S. Žižek, Pandemic! Covid-19 Shakes de World, New York, Or Books, 2020. Cf., mi reseña al libro en: "Pandemia. La covid-19 estremece al mundo de Slavoj Žižek", en Revista Bioética Complutense 39 (2020) pp. 69-70. Alli explico el problema de la traducción al castellano y catalán por parte de Anagrama del título mismo de este libro; lo traducen sin exclamaciones.

"... los virus no son formas elementales de vida de las que surgen otras formas más complejas; son purmenre parásitos, se replican infectando a organismos más desarrollados (cuando un virus nos infecta a nosotros los humanos tan solo le servimos e fotocopiadora). Es en esta coincidencia de elemtnos opuestos -el elemental y el 
cotas no les hace nada; hoy más que nunca los europeos "amaron" con todo a sus perros, porque gracias a ellos pudieron salir de su aburrido confinamiento existencial), en tan sólo 6 meses nos está generando muchos dolor e incertidumbre, miles de muertos en todo el planeta y millones de contagiados (luego el virus es pandémico, pero nunca tan letal como la influenza, la malaria u otras enfermedades actuales), tiene colapsado los sistemas sanitarios de los países, el miedo confina en sus hogares a personas y familias (más de 3.000 millones confinados en más de 185 países en los tres primero meses de la Pandemia), cierre de las fronteras de los países y que, en definitiva, ha paralizado a este pequeño planeta en su distribución y producción de capital. ¿Está el Capitalismo en jaque como piensa Žižek en Pandemic!? ¿El miedo al contagio es la clave para terminar con el Capitalismo? ¿El miedo al otro, que nos confina, generará una mutación más radical a este Capitalismo imperante, una nueva forma de "amarnos", de "cuidarnos", de Comunismo?

\section{Nosotros los "hegelianos" según el filósofo esloveno}

Slavoj Žižek, como otros pensadores actuales, reflexiona filosóficamente, como es sabido, a la altura de los tiempos desde el método mismo de Hegel (la mal llamada "dialéctica"); es decir, lo lógico mismo que se expresa, en especial, de modo metódico en los tres volúmenes de la compleja obra, del pensador suabo, la Ciencia de la lógica: "Doctrina del Ser", 1812-1832 (Segunda Edición póstuma), que expresa lo inmediato, "Doctrina de la Esencia", 1813, que expresa lo mediato y "Doctrina del Concepto", $1816^{9}$, que indica el movimiento mismo de lo inmediato y lo mediato (lo que posibilita a ambos momentos; luego es anterior y constitutivo al ser y la esencia; me refiero: la libertad, el amor, el NosOtros, etc. ${ }^{10}$. Este Hegel no es el Hegel panlogicista (ni totalitario, ni universalista, ni de la negatividad abstracta, etc.), no es el Hegel que critica: Schelling, Feuerbach, el joven Marx, Kierkegaard, Bakunin, Heidegger, Arendt, Kojève, Deleuze, Zambrano, etc.

parasitario- donde reside el misterio de los virus: son un caso de lo que Schelling denominó «der nie aufhebbare Rest»: un resto de las formas más bajas de vida que surge como producto del mal funcionamiento de mecanismo superiores de multiplicación y los persigue (los infecta), un resto que no siempre puede reintegraese al momento subordinado de un nnivel superior [... viruses are not the elementary form of life out of which more complex developed; they are purely parasitic, they replicate themselves through infecting more developed organisms (when a virus infects us, humans, we simply serve as its copying machine). It is in this coincidence of the opposites -elementary and parasitic- that resides the mystery of viruses: they are a case of what Schelling called «der nie aufhebbare Rest»: a remainder of the lowest form of life that emerges as a product of malfunctioning of higher mechanisms of multiplication and continues to haunt (infect) them, a remainder that cannot ever be re-integrated into the subordinate moment of a higher level of life]". Ibidem, pp. 84-85.

$9 \quad$ Cf., R. Espinoza, "Hegel y las redes lógicas como diseñadoras de la realidad", en Anales, Vol. 33, No 2, 2016, pp. 583-603.

10 Cf., F. Duque, Historia de la Filosofia Moderna: La era de la crítica, Madrid, Akal, 2000. Y S. Žižek, Menos que nada. Hegel y la sombra del materialismo dialéctico, Madrid, Akal, 2015.
Žižek es bien tajante desde su segunda Tesis Doctoral que realizó en la Universidad de Paris 8 bajo la tutela de Miller en 1985 (y lo tenía muy claro también en su primera Tesis Doctoral de 1981) 11. “... Hegel está muy alejado de la imagen recibida del «panlogicismo»: ¡es una extraña «verdad especulativa» la que solo puede articularse, en el nivel de las palabras, en los encuentros fortuitos!(...) La verdad no debe buscarse en el nivel de la universalidad de los principios sino en el de la contingencia particular"12. Žižek realiza un cierto "remix" de Hegel, así como lo intentó Adorno en el siglo XX, como señala José María Ripalda en el libro Žižek Reloaded ${ }^{13}$ :

De allí que muchos autores contemporáneos como Fredric Jameson $^{14}$, Terry Eagleton ${ }^{15}$ y, en especial, Slavoj Žižek ${ }^{16}$ estén detenidamente leyendo y releyendo a Hegel para afrontar estos grandes temas planetarios. Al parecer ya no es posible salir de la "época" de este horizonte del tiempo presente en el que somos y vivimos atados a la ideología de turno, ya de derechas, ya de izquierdas. No se puede saltar sobre la propia sombra capitalista, pues estamos mirando nuestro rostro en una imagen reflejada de aguas ya estancadas del valor de cambio (así como el mito de Narciso); estamos ante el ser en su inmediatez indeterminada ${ }^{17}$, como diría Hegel en la "Doctrina del ser" (1812) de la Ciencia de la lógica (Wissenschaft der Logik, en adelante: $W d L)^{18}$.

Esa inmediatez en la que vivimos además nos subjetiva. Hegel lo dice con fórmula muy precisa: "Das Seyn ist das unbestimmte Unmittelbare" ("El ser es lo inmediato indeterminado") ${ }^{19}$. La inmediatez nos trae a presencia nuestro modo de ser en el mundo (dicho en heideggeriano), pero esa inmediatez en la que somos, nos subjetiva, y en ello nos ideologiza, porque esa inmediatez está mediatzada; siempre está mediatiza, son las lógicas que constituyen nuestras vidas (es la gran diferencia del hegellianismo con la fenomenología, la ontología, la biopolítica, etc.). Por eso, por ejemplo, cuando Žižek no cree en una causa aparentemente "buena" de lucha contra el sistema, una demanda de tipo cultural:

$11 \quad$ La Tesis de 1981 que realiza en Lubiana se llama: Las posibilidades de una vuelta materialista de Hegel en la teoría psicoanalitica. S. Žizek, Možnosti 'materialističnega obrata; Hegla v psihoanalitični teoriji: doktorska disertacija, Ljubljana, 1981.

12 S. Žižek, El más sublime de los histéricos, Buenos Aires, Paidós, 1993, p. 67.

13 "En este contexto la lectura de Hegel que ha propuesto Žižek en Less than Nothing cobra algunos rasgos creativos de remix más que de interpretación". J. M. Ripalda, "El punto", en R. Espinoza, y O. Barroso, Žižek reloaded. Políticas de lo radical, Madrid, Akal, 2018, p. 289.

14 Cf., F. Jameson, Las variaciones de Hegel. Sobre la Fenomenología del espiritu, Madrid, Akal, 2015.

15 Cf., T. Eagleton, La estética como ideología, Barcelona, Trotta, 2006.

16 Cf., S. Žižek, Menos que nada. Hegel y la sombra del materialismo dialéctico, Madrid, Akal, 2015.

17 Cf., R. Espinoza, "Hegel y las redes lógicas como diseñadoras de la realidad”, op. cit., y R. Espinoza, Hegel y las nuevas lógicas del Estado ¿Cómo se es revolucionario hoy?, Madrid, Akal, 2016.

18 R. Espinoza, Capitalismo y empresa. Hacia una Revolusión del NosOtros, Santiago de Chile, Libro Pascal, 2018, p. 29.

19 G.W.F. Hegel, Wissenschaft der Logik. Erster Teil. Die Objective Logik. Ersted Band. Die Lehre vom Sein (1832), Hamburg, Felix Meiner Verlag, 1985, p. 68. 
el feminismo, animalismo, veganismo, etc.; es porque esa demanda, más allá de ser "buena o no" en lo inmediato, en el fondo está "siempre" mediatizada. Por eso Hegel dice en su $W d L$ que: "Die Wahrheit des Seyns ist das Wesen" ("La verdad del ser es la esencia") ${ }^{20}$. Hay lógicas que despliegan esa demanda y esas lógicas son la propia historia del Capitalismo. Es el Capitalismo el medio, por antonomasia, de toda nuestra in-mediatez en la que vivimos. Y esto es fundamental para entender los libros de Žižek y de los teóricos críticos. En Žižek este momento hegeliano de su método ${ }^{21}$ funciona casi como un axioma; desde él reflexiona lo que acontece hoy ${ }^{22}$. Y lo podemos ver, incluso en la Pandemia de la Covid-19.

Y, además, el mismo Hegel le da a Žižek con su reflexión teológica cristiana, ya desde sus escritos de juventud (no solamente de la Fenomenología del espíritu, sino de textos anteriores a 1807), una visión del otro, del nosotros, de la comunidad. Y esto lo realiza desde la idea de amor como clave metódica para entender la articulación de unos con otros que funda el tejido sociohistórico (ahí ya se ven los momentos del método: lo inmediato, lo mediato, el movimiento libre de lo mediato y lo inmediato); y aquí Žižek ve, en parte, la salida al Capitalismo actual; a saber, por vía de su llamado "Comunismo".

\section{3. "Amor" en tiempos de Covid-19}

Žižek en su reciente libro Pandemic! Covid-19 Shakes the World nos muestra, de modo ejemplar, la articulación de entrada que hay, por una parte, con el carácter inmediato del confinamiento por la Cuarentena mundial que realizan los Estados para que los humanos no nos toquemos, no nos contagiemos (Estados que devienen altamente militarizados como el Chino), pues los sistemas sanitarios están totalmente colapsados (no está demás decir que dichos sistemas han sido destruidos por el propio Capitalismo a lo largo de décadas desde Chile a UK pasando por USA y Brasil); y en esa inmediatez del confinamiento y el Mandato existencial-legal ¡Teme!, ¡Teme al Otro!, porque el Otro te puede contagiar (y en eso, por debajo, se escucha algo así: ¿Te has contagiado? Ergo: ¡Te mueres! Porque el propio Estado no podrá salvarte con la sanidad pública desmantelada por las propias decisiones capitalistas) también se da, por otra parte, la mediación propia de que cada uno de nosotros lleva dentro de sí al Otro. Hegel dice en El Espiritu del Cristianismo y su destino (segunda edición 1798/99) algo muy importante para Žižek: “... in love man has found himself again in another" ${ }^{\prime 2}$. El Otro nos constituye, pero, a la vez, el Otro nos está prohibido, radicalmente hoy, por el virus SARS-CoV-2 y el miedo

20 G,W.F. Hegel, "Die Lehre vom Wesen", en Wissenschaft der Logik. Ersted Band. Die objective Logik (1812-1813), Hamburg, Felix Meiner Verlag, 1978, p. 241.

21 Cf., R. Espinoza, Hegel y las nuevas lógicas del mundo y del Estado. ¿Cómo se es revolucionario hoy?, op. cit.

22 Cf., R. Espinoza, "Hegel lector de Žižek y las nuevas lógicas del mundo y del Estado", en R. Espinoza y O. Barroso, Žižek Reloaded. Políticas de lo radical, op. cit.

23 G.W.F. Hegel, The Spirit of Christianity, p. 278. al contagio. Es una tremenda paradoja de estos tiempos no solamente ética y política, sino que es una paradoja existencial.

$\mathrm{Y}$ en esta paradoja de que por Mandato no debemos contagiarnos, por lo mismo, ya no nos tocamos, pero, a la vez, es imposible no tocarse porque lo propio humano, de modo constitutivo, va con el otro en tanto que Otro; y siempre, por tanto, nos tocamos radicalmente. Luego nos nace, nos surge, se nos abre la dimensión de "tocar", de alguna forma ${ }^{24}$, al Otro, por ejemplo, por medio de la mirada. En realidad es un mutuo tocarse cuando nos miramos. Žižek es bien claro y, a la vez, muy poético para señalar esta idea en su Pandemic!:

Hoy en día, sin embargo, en mitad de la epidemia de coronavirus, a todos se nos bombardea precisamente con llamamientos no solo a no tocar a los demás, sino a aislarnos, a mantener una distancia corporal adecuada. ¿Cuál es el significado de esta prohibición de "no me toques"? las manos no pueden acercarse a la otra persona; solo desde el interior podemos acercarnos unos a otros, y la ventana hacia el "interior" son nuestros ojos [Today, however, in the midst of the coronavirus epidemics, we are all bombarded precisely by calls not to touch others but to isolate ourselves, to maintain a proper corporeal distance. What does this mean for the injunction "touch me not"? Hands cannot reach the other person; it is only from within that we can approach one another - and the window onto "within" is our eyes $]^{25}$.

Nos tocamos por medio de nuestros ojos cuando nos miramos.

Y añadiría de cualquier tipo de mirada, no solamente empírica cuando nos miramos, a saber, de un lado de la calle al otro mientras paseamos a un perro (eso está permitido en la Cuarentena), sino, en especial, una mirada virtual por medio de las redes sociales, medios de comunicación Facebook, WhatsApp, etc., y radicalmente inconsciente, pues lo político, lo social habita allí (mejor dicho, el inconsciente es la "membrana" misma de los Otros). En ese tocarnos por medio, simbólicamente, de nuestros ojos acontece el movimiento del amor; lo que Hegel llama en su filosofía madura de la $W d L$ el "concepto"; el movimiento negativo de la mediación en la inmediatez misma y que por ello afirma y, por tanto, abre ${ }^{26}$. Žižek, en sus textos, constantemente cita este bello pasaje del joven Hegel; un pasaje que cobra más sentido que nunca en estos días de confinamiento, cuarentena, pandemia y miedo al Otro; por ejemplo, ante el sufrimiento que nos causa perder nuestra propia vida por estar contaminado:

24 Cf., C. Malabou, "Contagio", en R. Espinoza, y F. Angulo, Conceptos para disolver la educación capitalista, Barcelona, Terra Ignota, 2020. En prensa

25 S. Žižek, Pandemia. La covid-19 estremece al mundo, op. cit., pp. 9-10.

26 "El concepto se muestra, según lo considerado anteriormente, como la unidad del ser y de la esencia. La esencia es la primera negación del ser, que ha venido a ser por ello apariencia; el concepto es la segunda, o sea la negación de esa negación; por tanto, el ser restablecido, pero como la infinita mediación y negatividad del mismo en sí mismo". G.W.F. Hegel, Wissenschaft der Logik. Zweiter Band. Die Subjektive Logik (1816), Hamburg, Felix Meiner Verlag, 1981, p. 29. 
Durante estos días, cuando te encuentras con una persona cercana a ti (o incluso con un desconocido) y mantienes la distancia adecuada, una profunda miarada a los ojos del otro puede revelar algo más que un contacto íntimo. En uno de sus fragmentos de juventud, Hegel escribió: "El ser amado no se opone a nosotros, es uno con nuestro propio ser; nos vemos a nosotros solo con él, aunque ya no es un nosotros: es un acertijo, un milagro [ein Wunder], algo que no podemos comprender" [These days, when you meet someone close to you (or even a stranger) and maintain a proper distance, a deep look into the other's eyes can disclose more than an intimate touch. In one of his youthful fragments, Hegel wrote ${ }^{27}$ : "The beloved is not opposed to us, he is one with our own being; we see us only in him, but then again he is not a we anymore - a riddle, a miracle [ein Wunder], one that we cannot grasp"] $]^{28}$.

En esta mediación del Otro que nos constituye se da ese preciso otro en tanto que Otro, que se resiste a ser determinado inmediatamente por el Capitalismo. En la tensión del amor, el otro no solamente nos constituye in-mediatamente, sino que también nos abre a algo por venir, dicho en derrideano. Pero ¿qué sucede con el amor? ¿El amor en tiempos de Capitalismo? ¿El amor que acontece en la Cuarentena mundial por la Covid-19?

Para Žižek el amor es clave no solamente como elemento negativo que nos permite ver y diagnosticar el Capitalismo mismo en toda su horrorosa manifestación (el momento de negación de la esencia respecto del ser), sino que el amor es también la afirmación (es radicalmente "concepto"), el lugar en donde nos constituimos como humanos; en donde somos dignos, libres y abiertos:

El amor es típico de cómo tratamos de evitar los acontecimientos. La idea es cómo compartir una vida, el placer e, incluso, el amor, pero sin la caída. Por eso nos gustan las agencias matrimoniales o de contactos, el sexo seguro... Tenemos miedo de abrirnos a la imprevisibilidad. El amor o el sexo sin el encuentro sorprendente es como la masturbación, juegas contigo mismo y no te abres a los demás. Nuestro consumismo se organiza así: queremos sexo, pero seguro; cerveza, pero sin alcohol; café, pero sin cafeína; chocolate, sin grasa. Queremos jugar con seguridad ${ }^{29}$.

El amor seguro no es amor, es mera expresión del yo, de la "verdad de la certeza de sí mismo" que Hegel explica de forma notable en la Fenomenología, esto es, de nuestro yo en medio del Capitalismo actual, en donde ese medio se mienta en la articulación de dominación del Señor y el Siervo. En esa articulación de verdad y certeza que se expresa en la dominación capitalista de Señor y Siervo; esto es, lo que se llama hoy, de forma clarísima, como Patriarcado, no hay posibilidad alguna para el amor.

El Capitalismo hacendal es patriarcal, pues opera en tanto lógicas de dominación Señor y Siervo (Amo e in-

\footnotetext{
G.W.F. Hegel, "Entwürfe über Religion und Liebe", in Frühe Schriften, Werke 1, Frankfurt /M, Suhrkamp, 1986, p. 244.

28 S. Žižek, Pandemia. La covid-19 estremece al mundo, op. cit., p. 10

29 Entrevista a Slavoj Žižek, por Inés Martín Rodrigo, en el ABC, 17 de noviembre de 2014: https://www.abc.es/cultura/cultural/20141117/ abci-entrevista-slavoj-zizek-201411171214.html
}

quilino; Masculino y femenino). Y esto lo ha trabajado el feminismo actual y de forma muy precisa la filósofa catalana Laura Llevadot. En ese Capitalismo hacendalpatriarcal solo acontece un narcisismo tóxico de dominación y violencia, un acto de mera masturbación, nunca de relación sexual, nunca de amor. Y es muy interesante ver cómo en hechos tan deleznables como las violaciones podemos ver esa expresión radical capitalista de dominación narcisa; de una verdad que se cierra en su certeza y de allí no sale, no acontece la afirmación de lo libre, de lo abierto. La filósofa nos recuerda el hecho horroroso ocurrido en España de La Manada para mentar esta idea: "Las violaciones colectivas, como las de La Manada, evidencian tan sólo cómo a los hombres les gusta contemplarse los unos a los otros: fuertes, bien empalmados, agresivos, dominantes hasta el paroxismo. El otro, la víctima de turno, es sólo un pretexto para escenificar su narcisismo" 30 . En este Patriarcado capitalista, en esta relación Señor y Siervo no acontece Otro (es imposible la relación sexual anclado en este binomio, en esta dualidad, de dominación), luego no hay amor, sino masturbación violenta y narcisa, que es expresión del funcionar típico del Capitalismo. En ese "narcisismo" que nos relata la filósofa se esconde la imposibilidad de amar; es "masturbación capitalista" como dice Žižek; y no hay amor sin lo incierto y abierto que lo constituye.

En la soledad de ese yo enfermizo actual, que se cree que su certeza constituye el mundo, no está ese Otro que miramos y nos mira, como diría el joven Hegel. Llevadot es muy precisa para mostrar cómo ese Capitalismo patriarcal con su economía egoísta nos violenta a todos con la diferencia sexual, que un hegeliano diría del Señor y el Siervo; y que si miramos con detención no solamente afecta a la mujer, que la afecta radicalmente, sino que el propio hombre es parte de esa lógica capitalista hacendal $\mathrm{y}$, por ende, es parte de su destrucción como humano: "La diferencia sexual es lo que arruina la relación sexual... No hay relación sexual sin deconstrucción de la diferencia sexual. Lo que las putas nos cuentan son los estragos que produce en cada uno de nosotros, hombres y mujeres, homosexuales y heterosexuales, la vigencia del patriarcado, de una economía fálica que construye un modelo de masculinidad y de feminidad que no satisface a nadie. Los clientes quieren dominar y vejar para afirmar su virilidad autoimpuesta y siempre fracasada, quieren que les mientan y les digan que cumplen excelentemente con su masculinidad"31. Esa relación sexual más allá de la hacienda capitalista del Señor y el Siervo nos posibilita que esté por venir el amor; liberará no solo a la mujer, sino también al hombre. Aquí vemos cómo puede verse el actuar del concepto hegeliano en su afirmación liberadora en tanto ha negado la inmediatez del Capitalismo hacendal patriarcal en su lógica narcisa dual.

Lo que hay, como ve la filósofa, es un Señor dominando a un Siervo y en ello solamente intentando violen-

\footnotetext{
L. Llevadot, Jacques Derrida: Democracia y soberanía, Barcelona, Gedisa, 2020, p. 99.

31 L. Llevadot, "Masculinidad: ese continente oscuro", en el libro de Núria Güell (ed.), El mamporrero y otros síntomas, Gerona, Bòlit Editorial, 2020 (en prensa).
} 
tar al otro para verse reflejado en él (cual Narciso), pero sin que ese otro sea Otro que me abre, que me fuga, que me vuelve incierto, no seguro, por venir; pero como lo ve muy bien el duplo Hegel-Žižek; ese Señor necesita al Siervo para realizarse (es su perversión); no lo puede aniquilar del todo. Ese yo en medio del Capitalismo opera como si fuera el amor, pero no lo es, sino mera apariencia de amor que nos subjetiva realmente como narcisos dentro del horizonte capitalista patriarcal y se expresa como "su" verdad; pero ya no se trata de verdad (ni de metafísicas), sino de apariencia, de estar traspasado por ella. Y en ese movimiento mismo tratar de vivir una vida entre todos. Por esta razón, el filósofo esloveno es bastante rotundo para mostrarnos cómo Hegel es un gran maestro para nuestros días: "La lección fundamental de Hegel es que el problema ontológico clave no es el de la realidad sino el de la apariencia: no «¿Estamos acaso condenados al juego interminable de las apariencias o podremos penetrar a través del velo hacia su verdadera realidad subyacente?», sino «¿Cómo puedo -en medio de la realidad chata y estúpida que está aquí- emerger algo como la apariencia?»" ${ }^{32}$.

El amor se expresa como una cierta ruptura de la verdad de sí mismo, del yo cierto como el garante de la verdad, del yo capitalista hacendal patriarcal; es incertidumbre, una salida, a lo inespecífico; es lo abierto que siempre se fuga, siempre sangra; nos hace aparecer, nos vuelve visible, nos somatizamos los unos a los Otros en el cuerpo de la relación sexual y de allí al cuerpo social, al cuerpo histórico. Así lo dice Žižek en uno de sus últimos libros: "La única forma de que nosotros, los seres humanos, atrapados en la brecha de paralaje, rompamos con ella, es a través de la experiencia de la sexualidad, que, en su mismo fracaso a la hora de alcanzar este objetivo, nos permite tocar la dimensión de lo absoluto"33. El amor en su carácter de inespecificidad mantiene la herida de la vida de forma sana, corporal y física; lo inmediato está en su mediación aconteciendo, afirmando. El filósofo esloveno lo señala de la siguiente forma en su libro Acontecimiento: “... ¿qué es el «Espíritu», en esencia? La «herida» de la naturaleza: el espíritu de la subjetividad humana es el poder de diferenciar, de «abstraer», de despedazar y tratar como autónomo lo que en realidad es parte de una unidad orgánica. El Espíritu no es más que el proceso de superar la inmediatez natural y la unidad orgánica, el proceso de elaboración («mediación») de esta inmediatez, retirarse-en-sí-mismo o «quitarse» de él, de alienarse de él"34. Ese "Espíritu" es lo que expresa el amor en sentido fuerte, no capitalista ni patriarcal, esto es, en tanto que acontecimento de Otro que rompe la inmediatez mediatizada del narcisimo capitalista que nos violenta día a día; y es lo que puede darse hoy confinados bajo la Cuarentena mundial por la Covid-19. Si así fuera podríamos confiar que, a lo mejor, más que revoluciones que se se buscan para estos tiempos, podemos dar con un cierto Comunismo que

\footnotetext{
S. Žižek, Visión de paralaje, Buenos Aires, FCE, 2006, pp. 43-44.

33 S. Žižek, "Teorema II. El sexo como nuestro encuentro con el absoluto", en El sexo y el fracaso del absoluto, Barcelona, Paidós, 2020, p. 125

34 S. Žižek, Acontecimiento, Madrid, Sexto Piso, 2015, p. 51.
}

se exprese, poco a poco, en este encierro militarizado realizado por el Estado nación por el "bien" de todos nosotros para que no nos contagiemos ${ }^{35}$.

\section{Por favor, ¡por ahora no más revoluciones!}

El subtítulo de este artículo sobre Žižek es el texto de Hegel, y nunca citado por nadie; es el que está a la base de Marx, Benjamin, Žižek y tantos pensadores de los siglos XX y XXI; es el célebre texto de la repetición (Wiederholung) que mienta lo propio de la historia; y lo importante del texto es que manifiesta que no es solamente que no aprendemos nada de la historia, sino, incluso, lo hacemos de forma más chapuza, de farsa, de estupidez, etc.; la historia se repite y lo que era contigente luego se efectúa como necesario: "Durch die Wiederholung wird das, was im Anfang nur als zufällig und möglich erschien, zu einem Wirklichen und Bestätigten" "36. Antes de Freud y el psicoanálisis, Hegel ve con claridad total, estudiando a sus queridos romanos, que la repetición nos constituye históricamente; los momentos históricos decisivos se repiten; $y$, además, se repiten para peor (pues no hemos aprendido nada de ellos). La repetición expresa que lo que en un momento histórico, en su inicio, era meramente accidental o posible luego se vuelve realidad efectiva y se confirma (se establece). Por ejemplo, en Chile cuando la Dictadura de Pinochet diseña el modelo empresarial capitalista para administrar la jubilación de todos los chilenos (las llamadas AFP); ese artilugio después se volvió algo totalmente necesario y ya no se puede eliminar de la estructura económica que mueve al país por completo; incluso aunque gobierne la izquierda (Bachelet); lo que era contingente en su inicio luego se repite como una cierta verdad que estructura la realidad. $\mathrm{Y}$ al parecer ya no se puede cambiar el sistema de jubilación chileno porque sería la destrucción del soporte económico del país.

Por esta razón Žižek dice en su Pandemic!: "Hegel escribió que lo único que Podemos aprender de la his-

35 Cf., R. Espinoza, 37. "Pandemia, Capitalismo e Ideología", en Tomás Cámara, D. (Comp.), Covidosofia, Barcelona, Paidós, 2020, pp. 245-255.

36 G.W.F. Hegel, "Rom vom zweiten Punischen Kriege bis zum Kaisertum”, en Werke 12, Vorlesungen über die Philosophie der Geschichte (3. Teil, 2. Absch.: “, ad fin. [1830]), Frankfurt /M, Suhrkamp, 1970, p. 380. El texto completo de Hegel no tiene desperdicio, pues indica por qué se da la necesidad de elegir a un emperador cuando fracasa la revolución romana; esto es, lo posible se vuelve revolucionario: "Unmittelbar darauf aber zeigte es sich, daß nur einer den römischen Staat leiten könne, und nun mußten die Römer daran glauben; wie denn überhaupt eine Staatsumwälzung gleichsam im Dafürhalten der Menschen sanktioniert wird, wenn sie sich wiederholt. So ist Napoleon zweimal unterlegen, und zweimal vertrieb man die Bourbonen. Durch die Wiederholung wird das, was im Anfang nur als zufällig und möglich erschien, zu einem Wirklichen und Bestätigten". "Pero en seguida después se hizo patente que el Estado romano únicamente podía ser conducido por un hombre solo, y los romanos debieron rendirse a esta evidencia; como suele ocurrir en general: puede decirse que un cambio político queda sancionado, en la opinión de las personas, por el mero hecho de que vuelva a producirse de nuevo. Por ejemplo. Napoleón fue derrotado dos veces, y dos veces se expulsó a los Borbones. Aquello que al principio parecía tan sólo casual y fortuito, gracias a la repetición se convierte en algo real y confirmado". G.W.F. Hegel, Filosofia de la Historia, Barcelona, Ediciones Zeus, 1970 , p. 338 
toria es que no aprendemos nada de la historia, así que dudo que la epidemia nos haga más sabios [Hegel wrote that the only thing we can learn from history is that we learn nothing from history, so I doubt the epidemic will make us any wiser]"37. Así de estúpido es todo; aprendemos de la historia una repetición que se nos vuelve más desastroza, luego, en verdad, no aprendemos nada o, menos que nada. Pues la repetición nos puede traer la farsa misma, la chapuza total de la llegada como nuevo emperador de Luis Bonaparte en Francia en 1851. Antes los franceses y europeos vivieron la tragedia de Napoléon, pero luego los franceses, todos ellos, repiten, sin historia alguna, en la estupidez total, y el sobrino más inepto es llevado al poder total, para que Francia vuelva a ser la gran potencia imperial, pero Luis Bonaparte, como es sabido, era realmente un hombre muy limitado. Por eso Marx no sabe ya qué esperar de un proceso revolucionario. Está claro que el dictum de Hegel-Marx: "Hegel dice en alguna parte que todos los grandes hechos y personajes de la historia universal aparecen, como si dijéramos, dos veces. Pero se olvidó de agregar: una vez como tragedia y la otra como farsa" ${ }^{38}$, es muy actual en nuestros días. Hoy opera más que nunca con esta nueva "Teología capitalista", a lo Marvel (y sus héroes y Guerras y Cuarentena) ${ }^{39}$, que nos ideologiza en esta nueva ciudad global virtual chapuza; porque los "Luis Bonaparte" se multiplican por todo el planeta: Piñera, Duque, Bolsonaro, Bukele, Trump, Johnson, Mitsotakis, Orban, etc. Y si vemos lo que ha pasado con el Coronavirus vemos que se repite la misma política de Cuarentena, para evitar el contagio y el colapso de lo sanitario, en todos los lugares del planeta como si fuera un fractal. Hay dos tipos de contagio el del virus de la enfermedad y el de la ideología capitalista militar.

Y de allí que el pensador esloveno constantemente nos esté señalando en distintas partes (libros, artículos, conferencias, entrevistas, etc.) y de modo provocador, a contracorriente con la izquierda clásica teórica $\mathrm{y}$, a la vez, activista que: "A menudo cito a Walter Benjamin cuando decía que «cada ascenso del fascismo da testimonio de una revolución fallida». Esto quizá sea más pertinente hoy de lo que ha sido nunca"40. Esto es, a lo mejor ya no estamos en tiempos de la Tesis 11 de Las Tesis sobre Feuerbach de Marx, no estamos en tiempos de transformación de la realidad, de intentar realizar la revolución por el "bien" de todos. Žižek es muy enfático y en eso deja muchos "heridos" en el camino con sus entrevistas; lo dice de forma brutal: "Ah, la estúpida «Tesis 11» de Marx: «Los filósofos no han hecho más que interpretar de diversos modos el mundo, pero de lo que se trata es de transformarlo». Creo que hoy Marx diría: «En el siglo XX intentamos cambiar el mundo

S. Žižek, Pandemia. La covid-19 estremece al mundo, op. cit., p. 12.

38 K. Marx, 18 Brumario de Luis Bonaparte, Buenos Aires, C. S. Ediciones, 1999, p. 10. Escrito por Marx en diciembre de 1851-marzo de 1852. Publicado con su firma, como primer número de la revista Die Revolution en 1852, en Nueva York (Seg. Ed. 1869, y Ter. Ed. 1885 por Engels).

39 Cf., R. Espinoza, "Por qué Marvel es nuestro enemigo a superar. The Thanos Quest...", en Argumenta Philosophica (Herder), Vol. ${ }^{\circ}$ 1, 2020, pp. 51-68.

40 S. Žižek, Pedir lo imposible, Madrid, Akal, 2014, p. 120. con demasiado afán. Ahora deberíamos echarnos atrás e interpretarlo más». Lo cual es verdad. No sabemos por dónde pisamos. ¿Es China capitalismo o es algo nuevo? Yo creo que China anuncia una nueva forma autoritaria de capitalismo. Incluso EE.UU. con Trump, Putin, Erdogan... avanzan en esa dirección" ${ }^{41}$. Žižek en tanto remix de Hegel ahora quiere comprender, reflexionar, criticar lo que acontece con el Capitalismo; encerrado en Eslovenia por la Cuarentena escribe un libro sobre la Pandemia de la Covid-19 en esta era capitalista; ese es el pensador actual; ya no quiere transformar nada, sino escribir sobre la realidad en el movimiento de la realidad misma. En medio de la realidad misma, en medio de la Pandemia y el Capitalismo, Žižek escribe y reflexiona sobre tal Pandemia.

La Tesis revolucionaria fallará y lo hará de forma más estrepitosa que nunca en estos tiempos, pues lo que vendrá es una repetición fascista proclamada y buscada por todos; se va a votar en las elecciones presidenciales de los países por el discurso fascista. Por ejemplo, Benjamin tenía bien claro en 1930 que, al parecer, donde se manifiesta el fascismo es porque ha fracasado, de alguna forma, la izquierda; él sentía cómo acontecía el totalitarismo fascista en Europa en pleno siglo XX y era por una repetición de un fracaso rotundo de la izquierda en el pasado. Él lo dice literalmente así en Teorías del Facismo alemán; en fórmula distinta a Žižek, pero similar en su "espíritu": "And what these authors mean by nation is a ruling class supported by this caste, aa ruling class- accountable to no one, and least of all to itself, enthroned on high -which bears the Sphink-life countenance of the producer who very soon promises to be the sole consumer of his commodities. Sphink-life in appearance, the fascist nation thus take its place as a new economic mystery of nature alongside the old. But its old mystery of nature, far from revealing itself to their technology, is exposing its most threatening feature" ${ }^{\prime 2}$. El fascismo toma el lugar que ha dejado el fracaso de la izquierda en el pasado; y lo toma para luego no dejarlo; se ha vuelto necesario lo que era una posibilidad. Por eso Žižek insiste una y otra vez con este tema; no quiere más procesos revolucionarios porque no solamente fracasan, sino que mutan al Capitalismo mismo desde su interior y lo vuelven cada vez más indestructible que es lo que se ha visto en la actualidad con la Pandemia: "Si seguimos a Žižek y en ello a Lacan, lo que vemos a final de los años 60 y comienzos de los 70 del siglo XX en Europa y que se cristaliza en el Acontecimiento de Mayo del 68; es un proceso revolucionario fallido (para variar, por lo general fallan), por eso cuidado con las revoluciones, ya Žižek lo hace notar con preocupación constantemente y en múltiples partes (y no podemos olvidar el fracaso de Bachelet y su Nueva Mayoría en Chile, del PT y Lula

\footnotetext{
Entrevista, por Darío Prieto, a Slavoj Žižek en El Mundo, 15 de mayo de 2018: https://www.elmundo.es/cultura/literatura/2018/05/1 5/5afa0b9dca4741183d8b465d.html

42 Benjamin, W., "Theories of German Fascism", New German Critique, \# 17, Spring 1979, p. 127. Esto es lo que Žižek constantemente parafrasea en múltiples partes como: "Cada ascenso del fascismo da testimonio de una revolución fallida". Lo mismo pasa con el parafraseo de Marx de Hegel que se usa hoy a cada momento: "Primero como tragedia después como farsa".
} 
en Brasil, de Cristina y el kirchnerismo en Argentina, de Syriza y Tsipras en Grecia, de Iglesias y Podemos en España, la fracasada Primavera Árabe y el advenimiento de fundamentalismos, etc.) ${ }^{n+43}$.

Y se trata de una revolución fallida porque realmente produce una nueva mutación del Capitalismo (muta más que Son Gokú); una transformación que se podría ver como al Neoliberalismo o Capitalismo tardío. Aunque en Mayo del 68 se generan varios logros para los franceses, europeos, etc., en derechos laborales, estudiantiles, etc., sin embargo, independiente de esas mejoras para todos, lo que sucedió es que la propia subjetividad capitalista cambió y ahora nos ideologizamos todos como nuevos capitalistas. Y he aquí el grave problema no visto y por los "teóricos de izquierda". Y aconteció, dicho en lacaniano, el Mandato del: ¡Goza!: "Se liberaron en Francia, y luego por Europa, América, Asia, las fuerzas de diversión, de entretención, de espectáculo, de simplemente gozar, de liberar el cuerpo de las ataduras del Capitalismo explotador y reconstructor de Europa post Segunda Guerra Mundial (como una precuela de la austeridad actual que se busca imponer no solamente a Grecia, España, Portugal sino a todos los países). Y los líderes revolucionarios se sintieron «felices» (demasiado) de ser revolucionarios en el mercado-mundo de las nuevas revoluciones" ${ }^{\prime 4}$. Nació de este modo, de esta revolución chapucera, el mandato existencial de que divertirse es un valor necesario en y por sí mismo (el valor por excelencia, y no solamente de los jóvenes). $\mathrm{Y}$ en ello toda dimensión de la realidad se la llevó ese mismo Mandato nihilista del gozar necesariamente; se llevo hasta la propia revolución. ¡No quedó nada de ella! Por eso, es necesario reflexionar, como hace Žižek, sobre el amor en estos tiempos de Coronavirus y Capitalismo, porque, a lo mejor, es la única posibilidad de generar cambio real en el futuro. Porque después de la Pandemia, puede suceder que acontezca un Capitalismo patriarcal chino militarizado para todo el planeta; que los distintos Estados naciones vean en China el modelo a seguir y se "contagien" con ese Capitalismo absolutamente militarizado y chapuza y que luego lo que era una posibilidad devenga una necesidad planetaria. USA, Rusia, Turquía, como dice Žižek, miran a China y devienen cada día más Capitalismo patriarcal militarizado; y ahora con la Pandemia es una gran tentación realizar el sueño del control total por el "bien" de todos.

\section{Conclusión: devenimos muertos vivientes}

En Žižek afirmativamente se da una salida amorosa ( $\sin$ necesidad de proclamar una revolución), se sale afirmativamente por otro en tanto que Otro que supera la paralización capitalista de cada uno de nosotros confinados en la Cuarentena. Žižek en su Pandemic! es muy claro en esto y más allá de la ironía nos dice:

\footnotetext{
43 R. Espinoza, NosOtros. Manual para disolver el Capitalismo, op. cit., pp. 98-99.

$44 \quad$ Ibidem, p. 99.
}

\begin{abstract}
"No me toques", según Juan 20,17, es lo que le dijo Jesús a María Magdalena cuando ello lo reconoció después de su resurrección. ¿Cómo he de entender yo, un ateo cristiano confeso, esas palabras? En primer lugar, quiero asociarlas con la respuesta de Cristo cuando sus discípulos le preguntan cómo sabrán que ha vuelto, que ha resucitado. Cristo les dice que estará allí donde haya amor entre sus creyentes. Estará allí no coo una persona a la que se puede tocar, sino como el vínculo de amor y solidaridad entre la gente. De manera que "no me toques, toca y relaciónate con los demás en el espíritu del amor" ["Touch me not" is what, according to John 20:17, Jesus said to Mary Magdalene when she recognized him after his resurrection. How do I, an avowed Christian atheist, understand these words? First, I take them together with Christ's answer to his disciple's question as to how we will know that he is returned, resurrected. Christ says he will be there whenever there is love between his believers. He will be there not as a person to touch, but as the bond of love and solidarity between people -so "do not touch me, touch and deal with other people in the spirit of love"] $]^{45}$.
\end{abstract}

Aquí vemos su ateismo radical pero, diría, siempre "religioso" (en el fondo un europeo); es como si Žižek postula una religión cristiana del amor radicalmente "atea". En el cristianismo de Hegel, el esloveno ve los fundamentos de lo que él entiende como un Comunismo para estos tiempos post-pandemia. "Una cosa es segura: la solución no será el aislamiento ni la construcción de nuevos muros y posteriores cuarentenas. Hace falta una plena solidaridad incondicional y una respuesta coordinada a nivel global, una nueva forma de lo que antaño se llamó comunismo [One thing is sure: isolation alone, building new walls and further quarantines, will not do the job. Full unconditional solidarity and a globally coordinated response are needed, a new form of what was once called Communism]"'46. Žižek ve las bases para reflexionar sobre su anhelado Comunismo, a saber, una cierta religión que en su materialidad de unos singulares y solos con Otros se vuelve universal; sin trascendencia alguna (con un dios solitario que está muerto y en soledad y debe permanecer bien muerto: clavado en la cruz ${ }^{47}$, una religión materialista y finita que desde el amor funda histórica y silenciosamente la sociedad. Žižek así lo dice en El sexo y el fracaso del absoluto: “... deberíamos reivindicar el amor radicalmente exclusivo hacia el uno singular, un amor que hace descarrilar el suave fluir de nuestras vidas" ${ }^{\text {48 }}$. Hegel lo dice de forma nítida en su Fenomenología, al final: "Aber dieses stumme Fortweben des Geistes im einfachen Innern seiner Substanz, der sich sein Thun verbirgt, ist nur Eine Seite der Realisirung der reinen Einsicht" ${ }^{\prime 49}$.

S. Žižek, Pandemia. La covid-19 estremece al mundo, op. cit., p. 9. Ibidem, p. 62.

Cf., Ibidem, p. 103.

48 S. Žižek, "Teorema IV. La persistencia de la abstracción", en El sexo $y$ el fracaso del absoluto, op. cit., p. 427.

49 G.W.F. Hegel, Phänomenologie des Geistes, en Georg Wilhelm Friedrich Hegel, Hauptwerke in sechs Bänden, Bd. 2. Phänomenologie des Geistes, nach dem Text des Bandes 9 der historisch-kritischen Edition "Georg Wilhelm Friedrich Hegel. Gesammelte Werke", Meiner, Hamburg, 2015, p. 296. "Pero este silencioso y continuado tejer del espíritu en el interior simple de su sustancia, que se oculta a sí 
Ese tejido silencioso del espíritu, expresa el amor de unos con Otros. Y esto es el tema de Slavoj Žižek en su obra a lo largo de tantos años y hoy, más especial, cuando la humanidad vive una Pandemia y vive y se desvive en el Capitalismo. Y es un tema que atraviesa su obra ya en lo negativo como en lo afirmativo. En lo negativo, como señalé, Žižek muestra a lo largo de los años cómo el Capitalismo nos ha ideologizado y en ello estamos echados a su suerte. Pues al parecer no es posible no solamente cambiar individualmente sino lo social mismo está capturado por la producción del capital (es cosa de pensar lo que devino Syriza). Y está bastante claro que en nuestras manos no está nuestra propia salvación; es imposible. Lo humano ya individual como social-histórico no puede escapar al influjo subjetivador que nos ideologiza; por eso, por ahora, dejar de lado la revolución y estudiar y reflexionar y escribir. Y ahora mismo en la reflexión y confinados en nuestros hogares millones de humanos podamos ver como el amor es, a lo mejor, una salida posible. También es posible que repitamos lo peor y el planeta devenga capitalista hacendalpatriarcal militarizado chapuza, esto es, que el planeta devenga China-USA, pero también en este momento podemos, vía amor, abrir el espacio para la llegada intrínseca del Comunismo que lleva dentro de sí lo humano. Pero nunca dejemos de estar alertas, nuevamente Žižek reflexiona desde su querido Hegel: "Como Hegel suele recordarnos, al combatir al enemigo externo uno lucha ( $\sin$ saberlo) contra su propia esencia. De modo que, lejos de celebrar el compromiso en la lucha, la clave para Hegel es más bien que cada posición en pugna, cada toma de partido, debe basarse en una ilusión necesaria (la ilusión de que, una vez que el enemigo es aniquilado, alcanzaré la plena realización de mi ser)... el sujeto ideológico es incapaz de captar cómo toda su identidad depende de lo que percibe como un obstáculo" ${ }^{\circ 0}$. Si es así, no podemos aniquilar el Capitalismo porque es parte de nuestra propia ideología que nos ha subjetivado ya por siglos (es como un sedimento histórico que se vuelve físico; como si el "meme" deviene "gene"); debemos mantener de una forma viva esa imagen capitalista dentro de "nosotros", pero que no sea radical solamente "nosotros". Y para eso es importante que esté abierto ese "nosotros" en tanto que NosOtros para que en la lucha contra el Capitalismo podamos afirmar una cierta salida manteniendo, en parte, su propia historia; si esto no lo logramos, solamente viviremos como "sombras" después de esta Pandemia de Covid-19. Y la vida ya no será vida amorosa ni afirmativa en la mediación capitalista que se quiere superar, sino que la vida será simplemente "sueño de una sombra"... ¡Nihilismo capitalista!

A lo mejor, si volvemos a repetir lo peor, logramos eliminar lo humano por un simulacro tecnológico totalitario, a lo chino; y se cumpliría la metáfora profética del gran poeta Píndaro:

"Sueño de una sombra, es el hombre" (Píticas, VIII, 9597).

\section{Bibliografía}

Agamben, G.: https://ficciondelarazon.org/2020/02/27/giorgio-agamben-la-invencion-de-una-epidemia/

Benjamin, W., “Theories of German Fascism”, New German Critique, \# 17, Spring 1979.

Duque, F., Historia de la Filosofia Moderna: La era de la crítica, Madrid, Akal, 2000.

Eagleton, T., La estética como ideología, Barcelona, Trotta, 2006.

Espinoza, R., "Hegel y las redes lógicas como diseñadoras de la realidad”, en Anales, Vol. 33, N 2, 2016, pp. $583-603$.

-, Hegel y las nuevas lógicas del Estado ¿Cómo se es revolucionario hoy?, Madrid, Akal, 2016.

-, Capitalismo y empresa. Hacia una Revolusión del NosOtros, Santiago de Chile, Libro Pascal, 2018.

-, NosOtros. Manual para disolver el Capitalismo, Madrid, Morata, 2019.

-, "Pandemia, Capitalismo e Ideología", en Tomás Cámara, D. (Comp.), Covidosofía, Barcelona, Paidós, 2020, pp. 245-255.

-, "Por qué Marvel es nuestro enemigo a superar. The Thanos Quest...”, en Argumenta Philosophica (Herder), Vol. 1, 2020, pp. 51-68.

Espinoza, R., y Barroso, O., Žižek reloaded. Políticas de lo radical, Madrid, Akal, 2018.

Hegel, G.W.F., The Spirit of Christianity, Chicago Chicago University Press, 1948.

-, Filosofia de la Historia, Barcelona, Ediciones Zeus, 1970.

-, Fenomenología del espíritu, Ciudad de México, FCE, 1970.

-, "Rom vom zweiten Punischen Kriege bis zum Kaisertum", en Werke 12, Vorlesungen über die Philosophie der Geschichte (3. Teil, 2. Absch.: “, ad fin. [1830]), Frankfurt/M, Suhrkamp, 1970.

-, "Die Lehre vom Wesen”, en Wissenschaft der Logik. Ersted Band. Die objective Logik (1812-1813), Hamburg, Felix Meiner Verlag, 1978.

-, Wissenschaft der Logik. Zweiter Band. Die Subjektive Logik (1816), Hamburg, Felix Meiner Verlag, 1981.

-, Wissenschaft der Logik. Erster Teil. Die Objective Logik. Ersted Band. Die Lehre vom Sein (1832), Hamburg, Felix Meiner Verlag, 1985.

-, "Entwürfe über Religion und Liebe", in Frühe Schriften, Werke 1, Frankfurt/M, Suhrkamp, 1986.

-, Phänomenologie des Geistes, en Georg Wilhelm Friedrich Hegel. Hauptwerke in sechs Bänden, Bd. 2. Phänomenologie des Geistes, nach dem Text des Bandes 9 der historisch-kritischen Edition "Georg Wilhelm Friedrich Hegel. Gesammelte Werke", Hamburg, Felix Meiner Verlag, 2015.

Jameson, F., Las variaciones de Hegel. Sobre la Fenomenología del espíritu, Madrid, Akal, 2015.

mismo su obrar, es solamente un lado de la realización de la pura intelección". G.W.F. Hegel, Fenomenología del espíritu, Ciudad de México, FCE, 1970, pp. 321-322.
50 S. Žižek, "Parte Segunda. La Cosa en sí: Hegel”, en Menos que nada. Hegel y la sombra del materialismo dialéctico, op. cit., p. 223. 
Llevadot, L., Jacques Derrida: Democracia y soberanía, Barcelona, Gedisa, 2020.

-, "Masculinidad: ese continente oscuro", en el libro de Núria Güell (ed.), El mamporrero y otros síntomas, Gerona, Bòlit Editorial, 2020

Malabou, C., "Contagio", en Espinoza, R. y Angulo, F., Conceptos para disolver la educación capitalista, Barcelona, Terra Ignota, 2020.

Marx, K., 18 Brumario de Luis Bonaparte, Buenos Aires, C. S. Ediciones, 1999.

Ripalda, J.M., "El punto”, en Espinoza, R., y Barroso, O., Žižek reloaded. Políticas de lo radical, Madrid, Akal, 2018, pp. 285291.

Žižek, S. Možnosti 'materialističnega obrata; Hegla v psihoanalitični teoriji: doktorska disertacija. Ljubljana, 1981.

-, El más sublime de los histéricos, Buenos Aires, Paidós, 1993.

-, Entrevista a Slavoj Žižek, por Inés Martín Rodrigo, en el ABC, 17 de noviembre de 2014: https:/www.abc.es/cultura/ cultural/20141117/abci-entrevista-slavoj-zizek-201411171214.html

-, Pedir lo imposible, Madrid, Akal, 2014.

-, Menos que nada. Hegel y la sombra del materialismo dialéctico, Madrid, Akal, 2015.

-, Acontecimiento, Madrid, Sexto Piso, 2015.

-, Entrevista, por Darío Prieto, a Slavoj Žižek en El Mundo, 15 de mayo de 2018: https://www.elmundo.es/cultura/literatura/20 18/05/15/5afa0b9dca4741183d8b465d.html

-, El sexo y el fracaso del absouto, Barcelona, Paidós, 2020.

-, Pandemia. La covid-19 estremece al mundo, Barcelona, Anagrama, 2020.

-, Pandemic! Covid-19 Shakes de World, New York, Ney Or Books, 2020. 